\title{
Two- and Three-dimensional Methods for the Assessment of Ballast Mats, Ballast Plates and Other Isolators of Railway Vibration
}

\author{
Lutz Auersch \\ Federal Institute of Materials Research and Testing (BAM), D 12200 Berlin, Germany
}

(Received 29 August 2005; accepted 15 September 2006)

This contribution gives a simple two-dimensional method to calculate the dynamics of railway tracks which have been checked against the results of completely three-dimensional finite-element boundary-element calculations. The forces generated by the train are modified, amplified or reduced, by the vehicle-track interaction and the force transfer of the track, yielding the forces that are acting on the ground and exciting the ground-borne vibration. The overall force transfer function, which is the integral of all forces acting on the soil divided by the input force on the vehicle, is presented for a number of different track systems. Details are given for the track with ballast mats where the influence of wheel mass, track mass, subsoil condition, and the stiffness of the mat have been analysed. Experimental results of the Federal Institute of Materials Research and Testing and literature are used to check the theoretical results about ballast mats.

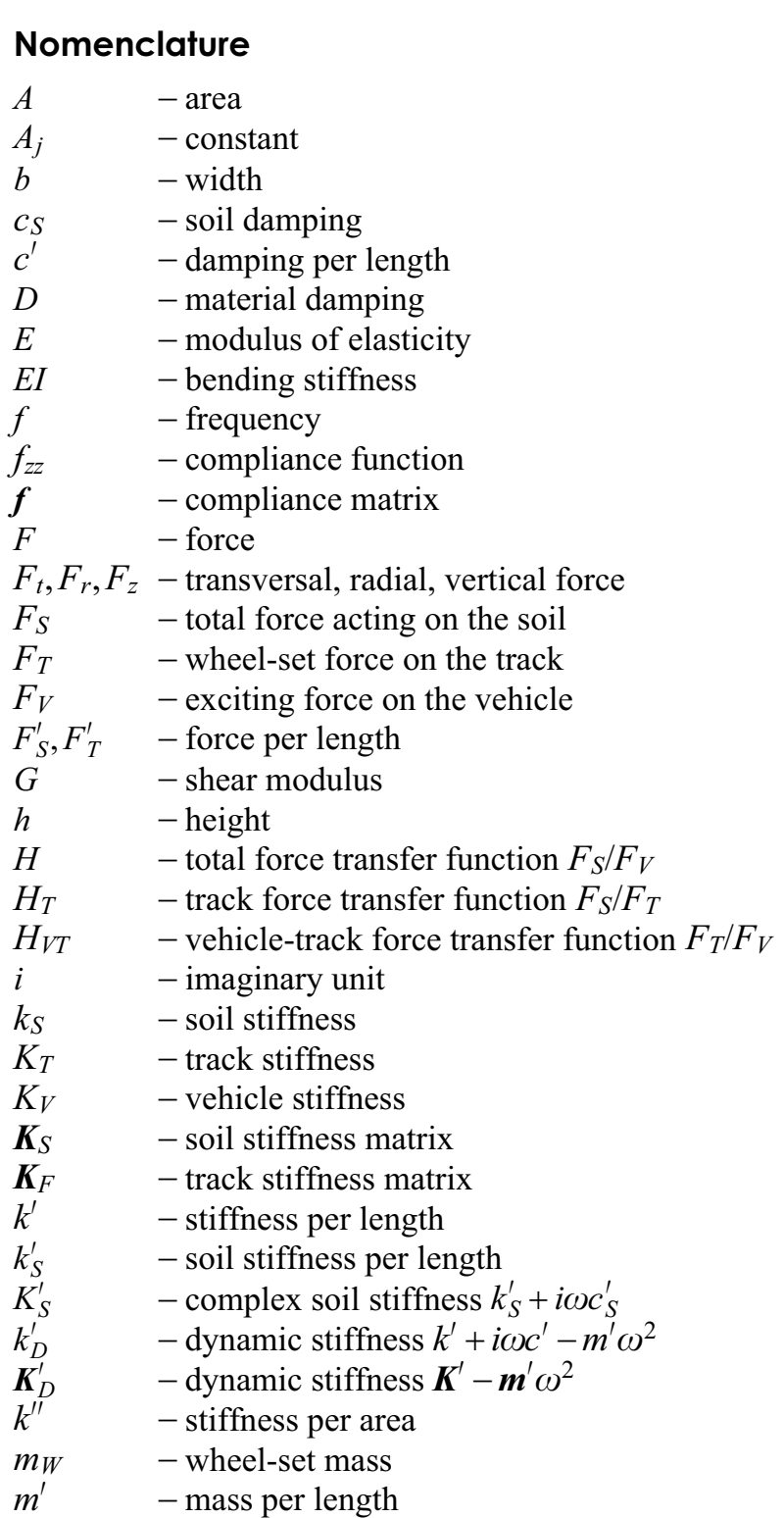

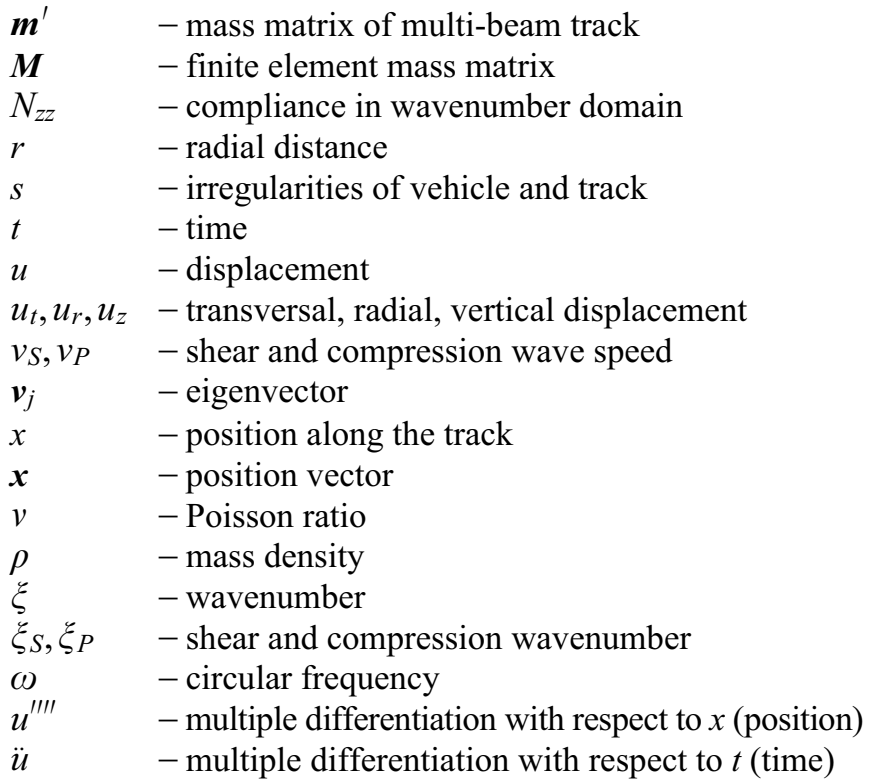

\section{INTRODUCTION}

A variety of isolation measures exists to reduce the vibration in the neighbourhood of railway lines. They can be roughly classified as elastic or stiffening systems. The following elastic elements are used (Fig. 1): railpads or resilient fixation systems between rail and sleeper, ${ }^{1}$ sleeper shoes under the sleepers, ${ }^{2}$ and ballast mats under the ballast ${ }^{1,3,4}$. Stiffening systems (plates) are used as slab tracks, ${ }^{5-7}$ floating slab tracks, ${ }^{\mathbf{1 , 8}, 9}$ or mass-spring systems ${ }^{\mathbf{1 0}}$ and in a different way, as an under ballast plate ${ }^{11-13}$. The main interest of this contribution is ballast mats.

Ballast mats are an efficient measure to reduce the vibrations near railway lines. The vehicle-track system gets a low eigenfrequency due to the insertion of an elastic ballast mat under the ballast. For frequencies higher than this low vehicle-track eigenfrequency, the forces, that are generating the vibration of the soil, are considerably reduced. 